\title{
The seasonal and solar cycle variations of electron density gradient scale length, vertical drift and layer height during magnetically quiet days: Implications for Spread $\boldsymbol{F}$ over Trivandrum, India
}

\author{
G. Manju, C. V. Devasia, and Sudha Ravindran \\ Space Physics Laboratory, Vikram Sarabhai Space Centre, Trivandrum-695 022, Kerala, India \\ (Received May 19, 2009; Revised September 8, 2009; Accepted September 15, 2009; Online published January 18, 2010)
}

\begin{abstract}
A study has been carried out on the behaviour of electron density gradient scale length, $L$, vertical drift and layer height, around post sunset hours, during the magnetically quiet days of summer, winter and equinox seasons of solar maximum (2002) and minimum years (1995), using ionosonde data of Trivandrum $\left(8.5^{\circ} \mathrm{N}, 76.5^{\circ} \mathrm{E}\right.$, dip $\left.=0.5^{\circ} \mathrm{N}\right)$ in the Indian longitude sector. The results indicate a clear seasonal and solar cycle variation in all the three parameters. Further, the seasonal variation of equatorial Spread $F$ (ESF) during the above period is examined in terms of the relative roles of $L$, the vertical drift and layer height (of the $F$ layer) in the triggering of the collisional Rayleigh-Taylor instability. The results, show for the first time, that $L$ also plays an important role, in controlling the quiet time seasonal and solar cycle variability of ESF; whereas in earlier studies this parameter had been taken to be constant. The detailed results are presented and discussed.
\end{abstract}

Key words: Equatorial ionosphere, ionospheric irregularities, plasma instability, equatorial Spread $F$.

\section{Introduction}

Equatorial Spread $F$ (ESF) irregularities are plasma density irregularities of scale sizes ranging from centimetres to several hundred kilometres observed in the night time $F$ region (Chandra and Rastogi, 1970; Farley et al., 1970; Woodman and LaHoz, 1976; Fejer and Kelly, 1980; Abdu et al., 1981; Kelley and McClure, 1981; Fejer et al., 1999; Hysell and Burcham, 2002). Studies have shown that plasma instabilities play a major role in the generation of these irregularities. The primary process responsible for the generation of the irregularities is the Collisional RaleighTaylor (CRT) instability mechanism operating in the post sunset bottom side $F$ region under certain favourable conditions (Haerendel, 1973). These conditions include the movement of the $F$-layer to very high altitudes in the postsunset hours, and/or formation of steep bottom side $F$-layer electron density gradient. Aspects related to the effect of meridional winds, on ESF occurrence, have been examined by some workers (Maruyama and Matuura, 1984; Devasia et al., 2002; Jyoti et al., 2004; Manju et al., 2007). Studies on the role of seed perturbations, in the generation of $F$ region irregularities have been reported by Whitehead (1971) and Fejer et al. (1999). In earlier studies, the seasonal pattern of occurrence of ESF, during magnetically quiet period, had been examined (Subbarao and Krishna Murthy, 1994), but the implications of the seasonal variations of electron density gradient scale length $L$, had not been considered. Manju et al. (2009) have examined the seasonal and solar activity dependence of $L$ and its modulation of ESF

Copyright (c) The Society of Geomagnetism and Earth, Planetary and Space Sciences (SGEPSS); The Seismological Society of Japan; The Volcanological Society of Japan; The Geodetic Society of Japan; The Japanese Society for Planetary Sciences; TERRAPUB. for magnetically disturbed days. They have shown that $L$ has clear seasonal variability in both the solar epochs (with maximum values in winter and minimum values in summer) and hence it modulates the seasonal pattern of ESF occurrence.

This paper presents, the first time estimates of the seasonal variations of electron density scale length, $L$ of the $F$ layer for the magnetically quiet days of solar minimum (1995-1996) and maximum (2002-2003) years. The expression for $L$ is given by,

$$
L=[(1 / n)(d n / d h)]^{-1}
$$

where, $n$ is the electron density, $h$ is the height and $(d n / d h)$ is the electron density gradient.

The role of the collisional Rayleigh-Taylor (CRT) instability mechanism in producing the observed seasonal occurrence pattern of ESF is also being examined here for magnetically quiet days. The expression for the growth rate of the generalized $\mathrm{R}-\mathrm{T}$ instability in terms of different forcing parameters is given as shown below by Sekar and Raghavarao (1987)

$$
\gamma=1 / L\left[g / v_{\text {in }}+\mathbf{E}_{x} / \mathbf{B}+\mathbf{W}_{x}\left(v_{\text {in }} / \Omega_{i}\right)-\mathbf{W}_{z}\right]
$$

Where, $\mathbf{E}_{x}$ is the zonal electric field, $\mathbf{B}$ is the geomagnetic field, $g$ is the acceleration due to gravity, $v_{\text {in }}$ is the ionneutral collision frequency, $\Omega_{i}$ is the gyrofrequency, $\mathbf{W}_{x}$ and $\mathbf{W}_{z}$ are the zonal and vertical winds respectively. The role of winds and seed perturbations modulate the day-today occurrence pattern of ESF, even on days when the first term in Eq. (2) is unfavourable. In the present study, we are examining how far the collisional Rayleigh-Taylor (CRT) mechanism can account for the general seasonal pattern of ESF during magnetically quiet periods, considering the 
variabilities only in $L$ and $v_{\text {in }}$. Here the appearance of Spread in the $F$ layer traces in the period between 1830$2100 \mathrm{hr}$ is taken as ESF occurrence.

\section{Experimental Set Up and Data and Method of Analysis}

Ionosonde data, of Trivandrum $\left(8.5^{\circ} \mathrm{N}, 76.5^{\circ} \mathrm{E}\right.$, dip latitude $0.5^{\circ} \mathrm{N}$ ) obtained at $15 \mathrm{~min}$ intervals, in the Indian longitude sector, have been made use of in this study. The available ionosonde data for the northern summer, northern winter and autumnal equinox seasons of 1995-96 (solar minimum) and 2002-2003 (solar maximum) have been examined. In the remaining part of this paper, equinox refers to autumnal equinox (September-October), summer to northern summer and winter to northern winter. Generally, the patterns of variability of different parameters, for both the equinoxes are similar. Hence only autumnal equinox has been analyzed in this study.

The $L$ and $d\left(h^{\prime} F\right) / d t$ values in the post sunset period of each day are deduced from ionosonde data. There are no direct measurements of $v_{\text {in }}$. But, it is known that $v_{\text {in }}$ decreases with height, and an increased upward (downward) vertical drift necessarily indicates the movement of the layer into a region of lower (higher) $v_{\text {in }}$. Hence for this study, an upward vertical drift is taken to correspond with a decrease in $v_{\text {in }}$ and vice versa.

To estimate $L, d n / d h$ is obtained by considering the virtual heights of reflection at $2.5 \mathrm{MHz}$ and $3.5 \mathrm{MHz}$. The scaling accuracy of $h^{\prime} F$ is $3 \mathrm{~km}$. The error in $d n / d h$ obtained by using $h^{\prime} F$ instead of the true height is estimated to be less than 5\% (Krishna Murthy et al., 1990). The error is less because the difference between the virtual and true heights is rather small at these low frequencies, during the night time, as the underlying ionisation is negligible. The vertical drift of the $F$ layer is obtained by deducing $d\left(h^{\prime} F\right) / d t . d t$ represents the time interval between $1800 \mathrm{hr}$ and the time of occurrence of maximum layer height in the post sunset period. $d\left(h^{\prime} F\right)$ is the difference between the maximum layer height in the post sunset period and the layer height at $1800 \mathrm{hr}$. Here the vertical drift due to recombination effects is neglected as it is not significant in relation to the large vertical drift due to pre-reversal enhancement of the zonal electric field (Tulasi Ram et al., 2006). The $L$ and maximum $d\left(h^{\prime} F\right) / d t$ values are estimated for available data on each day, corresponding to the three seasons of solar minimum (1995-1996) and solar maximum (2002-2003) years. The maximum vertical drift in the post sunset hours and the $L$ value at $1900 \mathrm{hr}$ on each day are used to interpret the seasonal pattern of ESF for quiet days.

\section{Results}

In the present study, the days with $A_{\mathrm{p}}<18$ are considered as magnetically quiet days.

\subsection{Seasonal variation of $\boldsymbol{L}$ for magnetically quiet days}

Figure 1 depicts the seasonal variation of mean $L$ for the magnetically quiet days of solar minimum and maximum epochs. The mean $L$ value is maximum during equinox and minimum during summer for solar maximum. For solar minimum, $L$ is maximum in winter and minimum in summer. During solar minimum the mean $L$ value increases

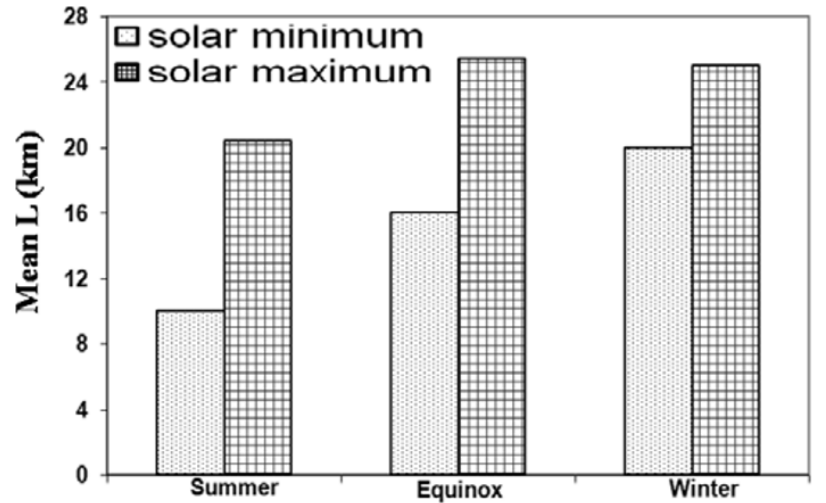

Fig. 1. Seasonal variation of post sunset mean $L$ for magnetically quiet days of solar minimum and maximum.

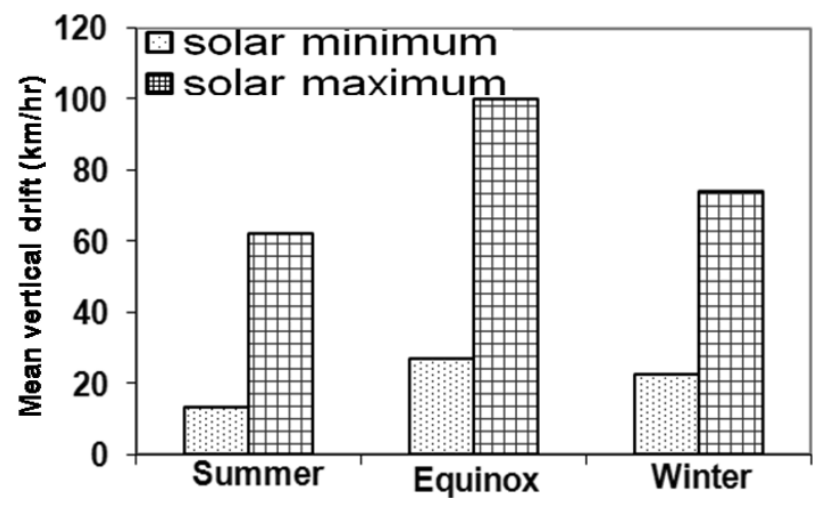

Fig. 2. Seasonal variation of post sunset mean vertical drift $\left(d\left(h^{\prime} F\right) / d t\right)$ for magnetically quiet days of solar minimum and maximum.

from $10 \mathrm{~km}$ in summer to $16 \mathrm{~km}$ in equinox and to $20 \mathrm{~km}$ in winter. In solar maximum, the mean $L$ value increases from $20 \mathrm{~km}$ in summer to $\sim 25 \mathrm{~km}$ in equinox/winter.

\subsection{Seasonal variation of mean vertical drift for mag- netically quiet days}

The seasonal mean of the maximum vertical drift (obtained by averaging the vertical drift on the individual days of each season) in the post sunset hours for the magnetically quiet period of solar minimum and maximum epochs are shown in Fig. 2. The seasonal mean vertical drift velocity is maximum in equinox, and minimum in summer for both the solar epochs. In solar minimum, the vertical drift increases by nearly $20 \%$ from winter to equinox and nearly $35 \%$ from summer to equinox, while in solar maximum it increases by $\sim 65 \%$ (from summer to equinox) and by nearly $36 \%$ from winter to equinox. Thus the vertical drift is most favourable for ESF occurrence during equinox in both epochs.

\subsection{Seasonal variation of mean $F$ layer height for mag- netically quiet days}

The seasonal mean of the maximum $F$ layer height (obtained by averaging the layer height on the individual days of each season) in the post sunset hours for the magnetically quiet period of solar minimum and maximum epochs are shown in Fig. 3. The seasonal mean layer height is maximum in equinox, and minimum in summer for both the solar epochs. For solar minimum the range of variability of layer height is much larger $(\sim 50 \mathrm{~km})$ than in solar maxi- 


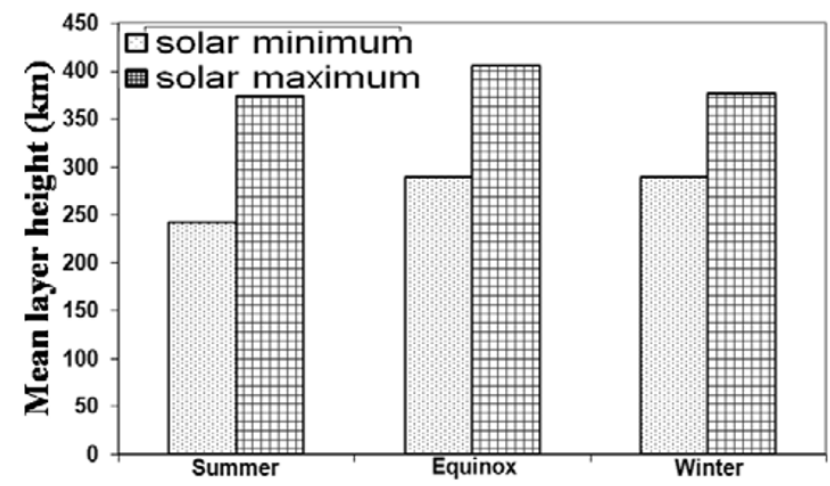

Fig. 3. Seasonal variation of post sunset mean layer height for magnetically quiet days of solar minimum and maximum.

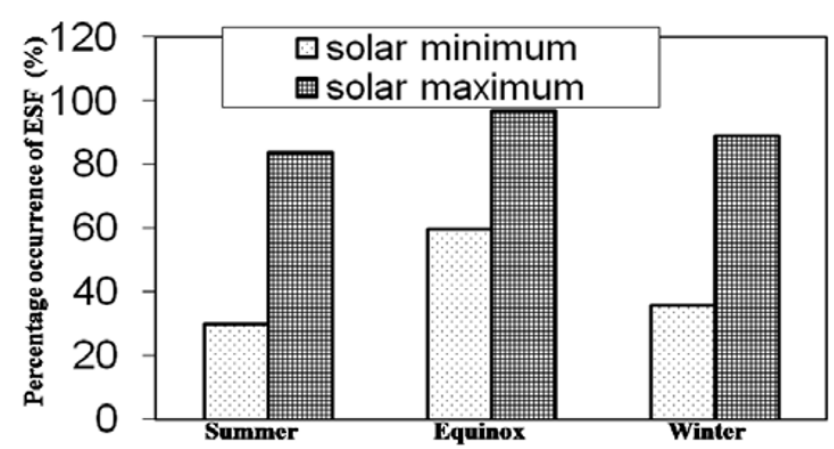

Fig. 4. Seasonal variation of percentage occurrence of ESF for magnetically quiet days of solar minimum and maximum.

mum $(\sim 30 \mathrm{~km})$. This is because the layer height is very low during summer of solar minimum.

3.4 Seasonal variation in ESF occurrence pattern during magnetically quiet days of solar minimum and maximum epochs

The seasonal mean percentage occurrence of ESF, during magnetically quiet days of solar minimum and maximum are shown in Fig. 4. The percentage occurrence is maximum in equinox and minimum in summer for both solar epochs. The seasonal mean percentage occurrence of ESF is examined in the next section in conjunction with the seasonal mean behavior of the electron density gradient scale length $L$ and $\left[d h^{\prime} F / d t\right]_{\max }$ to understand how far the collisional RT instability alone suffices to explain the general pattern of ESF occurrence in a given season and solar epoch.

\section{Discussion}

The seasonal pattern of $L$, vertical drift layer height and ESF occurrence percentage for equinox, summer and winter are represented in table form in Table 1, Table 2 and Table 3 respectively. For the equinox season, the mean $L$ value increases by a factor of $\sim 1.6$ from solar minimum to maximum, which means it is much less favourable for ESF. Correspondingly, the mean $\left[d h^{\prime} F / d t\right]_{\max }$ value increases by a factor of $\sim 3.7$. The vertical drift is more favourable for ESF in solar maximum, but the $L$ parameter has an inhibiting effect. The layer height is also very much higher by $\sim 115 \mathrm{~km}$ in solar maximum. The dominant effect of the increased vertical drift at solar maximum gives rise to the increased percentage occurrence in equinox of solar maximum.

For summer season, it is seen that the mean $L$ value increases by a factor of $\sim 2$ in solar maximum compared to solar minimum. The corresponding vertical drift increases by a factor of $\sim 4.6$. The favourable larger value of vertical drift in summer of solar maximum results in increased percentage occurrence of ESF compared to solar minimum period. The layer height is also larger in solar maximum by $131 \mathrm{~km}$. The increased post sunset vertical drift is the most dominant factor and it seems to give rise to the increased percentage occurrence of ESF in summer of solar maximum compared to minimum.

For the winter season, the mean $L$ value increases by $\sim 1.3$ times from solar minimum to solar maximum, which means it is less favourable for ESF in solar maximum. Correspondingly the mean $\left[d h^{\prime} F / d t\right]_{\max }$ value increases by $\sim 3.3$ times. In addition to this the layer height itself is much higher in winter of solar maximum. Thus for winter also the dominant role of the vertical drift seems to give rise to the higher percentage occurrence of ESF in solar maximum.

The seasonal pattern of $L$ and vertical drift in a given epoch is analyzed to interpret the observed seasonal ESF occurrence pattern. During solar minimum, the $L$ value increases by $\sim 1.6$ times from summer to equinox while the vertical drift increases by 2 times. That is, during equinox the vertical drift factor is favourable for ESF while $L$ factor inhibits ESF. The mean layer height is also higher in equinox by $\sim 50 \mathrm{~km}$ when compared to summer. The higher percentage occurrence of ESF being observed in equinox $(61 \%)$ in relation to summer $(30 \%)$ indicates that the unfavourable effect of increased $L$ in equinox is offset by the favourable effect of the vertical drift and layer height on the growth rate of the collisional RT instability.

The mean $L$ value increases by $\sim 2$ times from summer to winter in solar minimum, while the mean $\left[d h^{\prime} F / d t\right]_{\max }$ value correspondingly increases by a factor of $\sim 1.7$. Here $L$ is unfavourable and $\left[d h^{\prime} F / d t\right]_{\max }$ is favourable for the RT instability growth during winter in comparison to that in summer. But the mean layer height in winter is higher by $\sim 46 \mathrm{~km}$ than that in summer which means that the layer is at a level of more favourable $v_{\text {in }}$ in winter than summer. The combined effect of the increased vertical drift and the layer height offsets the inhibiting effect of $L$ on the growth rate thus resulting in a slightly higher ESF percentage occurrence of $36 \%$ in winter compared to the $30 \%$ observed in summer.

In the case of solar maximum, the mean $L$ value increases from summer to equinox by around 1.3 times, while the mean $\left[d h^{\prime} F / d t\right]_{\max }$ value increases $\sim 1.6$ times. The inhibiting effect of higher $L$ is offset by the higher and favourable vertical drift in equinox. Moreover the layer height in equinox (of solar maximum) is higher by $\sim 31 \mathrm{~km}$ compared to that in summer. The favourable effect of vertical drift and the layer height results in an ESF occurrence percentage of $97 \%$ in equinox in comparison to $84 \%$ in summer of solar maximum.

Coming to the pattern of variability from summer to winter in solar maximum epoch, it is seen that the mean $L$ value increases by a factor of $\sim 1.2$ from summer to winter in so- 
Table 1 . Solar activity variations of $L$, layer height and vertical drift for equinox.

\begin{tabular}{lccc}
\hline \multicolumn{1}{c}{ Equinox } & Solar minimum & Solar maximum & Percentage change \\
\hline$L(\mathrm{~km})$ & 16 & 25.4 & 58.8 \\
Layer height $(\mathrm{km})$ & 290 & 405 & 39.7 \\
Vertical drift $(\mathrm{km} / \mathrm{hr})$ & 27 & 100.5 & 272.2 \\
ESF occurrence $(\%)$ & 61 & 97 & 59 \\
\hline
\end{tabular}

Table 2. Solar activity variations of $L$, layer height and vertical drift for summer.

\begin{tabular}{lccc}
\hline \multicolumn{1}{c}{ Summer } & Solar minimum & Solar maximum & Percentage change \\
\hline$L(\mathrm{~km})$ & 10 & 20.4 & 104 \\
Layer height $(\mathrm{km})$ & 243 & 374 & 53.9 \\
Vertical drift $(\mathrm{km} / \mathrm{hr})$ & 13.5 & 62.3 & 361.5 \\
ESF occurrence $(\%)$ & 30 & 84 & 180 \\
\hline
\end{tabular}

Table 3. Solar activity variations of $L$, layer height and vertical drift for winter.

\begin{tabular}{lccc}
\hline \multicolumn{1}{c}{ Winter } & Solar minimum & Solar maximum & Percentage change \\
\hline$L(\mathrm{~km})$ & 20 & 25 & 25 \\
Layer height $(\mathrm{km})$ & 289 & 376 & 30.1 \\
Vertical drift $(\mathrm{km} / \mathrm{hr})$ & 22.5 & 74.4 & 230.7 \\
ESF occurrence $(\%)$ & 36 & 89 & 147.2 \\
\hline
\end{tabular}

lar maximum, with the mean $\left[d h^{\prime} F / d t\right]_{\max }$ value also correspondingly increasing by a factor of 1.2 . The mean layer height is nearly equal in summer and winter of solar maximum. But, during periods of high solar activity the scale height $(H)$ of the neutrals in the $F$ region changes significantly due to the increase in temperature $(H=R T / M g)$, where $R$ is the gas constant, $T$ is the temperature in ${ }^{\circ} \mathrm{K}, M$ is the molecular mass and $g$ the acceleration due to gravity. The increase in $H$ with increasing solar activity results in a swelling of the thermospheric neutral densities (FullerRowell et al., 1996). As a result the ion-neutral collision frequencies would increase. This in turn, would result in a reduced growth rate of the RT instability (Eq. (2)) for a given altitude at solar maximum in comparison to that at solar minimum. This inhibiting effect is less in winter (Manju et al., 2007) and higher in equinox and summer (due to the higher temperatures). Hence this effect is probably, producing a slightly higher ESF percentage occurrence of $89 \%$ in winter compared to $84 \%$ in summer.

In this study, some of the factors controlling the generalized RT instability namely the role of the seed perturbations and winds have not been considered with a view to understand how far the $L$ and $v_{\text {in }}$ (as can be inferred from $\left.\left[d h^{\prime} F / d t\right]_{\max }\right)$ variability suffices to explain the mean seasonal pattern of ESF on magnetically quiet days. For both the epochs the combined effects of $L$ and $v_{\text {in }}$ are seen to be modulating the ESF occurrence pattern. For solar maximum, the temperature related effect on $v_{\text {in }}$ also seems to be important in controlling the same. Subbarao and Krishna Murthy (1994) have earlier examined the seasonal and solar cycle variation of ESF. They have analyzed the ESF occurrence patterns in terms of the growth rate being above or below zero over entire nighttime period. They had used a constant value of $L$ for all the growth rate estimates. The seasonal and solar cycle variability of ESF obtained in the present study agrees with that obtained in previous studies
(Subbarao and Krishna Murthy, 1994; Tulasi Ram et al., 2006). The inclusion of $L$ variability also in the growth rate estimates may be able to give better indication of ESF occurrence probability especially while considering on a dayto-day basis. The pattern of seasonal and solar activity variability of $L$ obtained for quiet days in this study, is similar to that obtained earlier for magnetically disturbed periods (Manju et al., 2009). This shows that seasonal mean $L$ is not drastically modulated by magnetic activity.

\section{Conclusions}

The present study brings out for the first time, the clearcut seasonal variation in $L$ for the magnetically quiet days of both solar minimum and maximum. The $L$ value is minimum in summer for both the solar epochs. It is maximum in equinox/winter of solar maximum and winter of solar minimum. The important role played by $L$ in association with vertical drift and layer height in modulating the seasonal and solar activity pattern of ESF occurrence is also unravelled. Off late, scientists are increasingly attempting, to quantify the background ionospheric conditions in the post sunset period, so that ESF prediction becomes more reliable. This is because the irregularities producing $L$ band scintillations, which are hazardous for navigation, are generated from the large scale size ESF irregularities. In the light of the above, the present study gives an indication that the variability in $L$ may also be an important parameter controlling equatorial Spread $F$.

Acknowledgments. The authors wish to acknowledge the referees for their valuable comments which helped greatly to improve the manuscript.

\section{References}

Abdu, M. A., I. S. Batista, and J. A. Bittencourt, Some characteristics of Spread F at the magnetic equatorial station Fortaleza, J. Geophys. Res., 86(A8), 6836-6842, 1981. 
Chandra, H. and R. G. Rastogi, Solar cycle and seasonal variation of Spread F near the magnetic equator, J. Atmos. Sol. Terr. Phys., 32, 439444, 1970.

Devasia, C. V., N. Jyoti, K. S. Viswanathan, K. S. V. Subbarao, D. Tiwari, and R. Sridharan, On the plausible linkage of thermospheric meridional winds with equatorial Spread F, J. Atmos. Sol. Terr. Phys., 64, 1-12, 2002.

Farley, D. T., B. B. Balsley, R. F. Woodman, and J. P. McClure, Equatorial Spread F: Implications of VHF radar observations, J. Geophys. Res., 75, 7199-7216, 1970.

Fejer, B. G. and M. C. Kelley, Ionospheric irregularities, Rev. Geophys Space Phys., 18, 401-454, 1980.

Fejer, B. G., L. Scheerliess, and E. R. de Paula, Effects of the vertical plasma drift velocity on the generation and evolution of equatorial Spread F, J. Geophys. Res., 104, 19859-19869, 1999.

Fuller-Rowell, T. J., M. V. Codrescu, R. J. Moffett, and S. Quegan, On the seasonal response of the thermosphere and ionosphere to geomagnetic storms, J. Geophys. Res., 101, 2343-2353, 1996.

Haerendel, G., Theory of equatorial Spread F, Report, Max-Plank inst. fur Phys. and Astrophys., Munich, 1973.

Hysell, D. L. and J. Burcham, Long term studies of equatorial spread F using the JULIA radar at Jicamarca, J. Atmos. Terr. Phys., 64, 15311543, 2002.

Jyoti, N., C. V. Devasia, R. Sridharan, and D. Tiwari, Threshold height (h'Fc) for the meridional wind to play a deterministic role in the bottom side equatorial Spread F and its dependence on solar activity, Geophys. Res. Lett., 31, L12809, doi:10.1029/2004GL019455, 2004.

Kelley, M. C. and J. P. McClure, Equatorial Spread-F: a review of recent experimental results, J. Atmos. Terr. Phys., 43, 427-435, 1981.

Krishna Murthy, B. V., S. S. Hari, and V. V. Somayajulu, Nighttime equa- torial thermospheric meridional winds from h'F data, J. Geophys. Res., 95, 4307-4310, 1990.

Manju, G., C. V. Devasia, and R. Sridharan, On the seasonal varations of the threshold height for the occurrence of equatorial Spread F during solar minimum and maximum years, Ann. Geophys., 25, 1, 2007.

Manju, G., C. V. Devasia, and S. Ravindran, The seasonal and solar cycle variations of electron density gradient scale length during magnetically disturbed days: implications for Spread F, Earth Planets Space, 61, 913-917, 2009.

Maruyama, T. and N. Matuura, Longitudinal variability of annual changes in activity of ESF and plasma depletions, J. Geophys. Res., 89, 10903109012, 1984.

Sekar, R. and R. Raghavarao, Role of vertical winds on the RayleighTaylor instabilities of the nighttime equatorial ionosphere, J. Atmos. Terr. Phys., 49, 981-985, 1987.

Subbarao, K. S. V. and B. V. Krishna Murthy, Seasonal variations of equatorial Spread F., Ann. Geophys., 12, 33-39, 1994.

Tulasi Ram, S., P. V. S. Rama Rao, K. Niranjan, D. S. V. V. D. Prasad, R. Sridharan, C. V. Devasia, and Sudha Ravindran, The role of post-sunset vertical drifts in predicting the onset of VHF scintillations during high and low sunspot activity, Ann. Geophys., 24, 1609-1616, 2006.

Whitehead, J., Ionization disturbances caused by gravity waves in the presence of an electrostatic field and background wind, J. Geophys. Res., 76, 238-241, 1971.

Woodman, R. F. and C. LaHoz, Radar observations of F region equatorial irregularities, J. Geophys. Res., 81, 5447-5466, 1976.

G. Manju (e-mail: manju_spl@vssc.gov.in), C. V. Devasia, and S. Ravindran 